\title{
Climatic, Environmental and Fire Behaviour (C2 E2 F1) Test of Cast Resin Transformer
}

\author{
Remya Krishnan, ", Muraleedharan Nair ${ }^{2}$ \\ ${ }^{1}$ Design Department, Federal Transformers Co. LLC., Abu Dhabi, UAE \\ ${ }^{2}$ Federal Transformers Co. LLC., Abu Dhabi, UAE \\ Email address: \\ remyakrishnn@gmail.com(R. Krishnan),krmurali2000@yahoo.com(M. Nair) \\ ${ }^{*}$ Corresponding author
}

\section{To cite this article:}

Remya Krishnan, Muraleedharan Nair. Climatic, Environmental and Fire Behaviour (C2 E2 F1) Test of Cast Resin Transformer. American Journal of Electrical Power and Energy Systems. Vol. 7, No. 1, 2018, pp. 11-15. doi: 10.11648/j.epes.20180701.12

Received: February 19, 2018; Accepted: March 5, 2018; Published: April 2, 2018

\begin{abstract}
The dry type cast resin transformer shall be suitable for usage under expected climate conditions. It shall be selfextinguishing and shall not produce toxic gases in the event of fire. This is verified by the Climatic, Environmental and Fire withstand behaviour test as per 60076-11. This paper gives the design features of a $1600 \mathrm{kVA}$ dry type cast resin transformer which was subjected to climatic, environmental and fire behaviour (C2 E2 F1) tests at KEMA testing laboratory, Netherlands. The technical parameters of epoxy resin system, winding configuration, and clamping, etc. necessary to meet the requirements are also discussed.
\end{abstract}

Keywords: Cast Resin Transformer, C2 E2 F1 Test, Dry Type Transformers, Special Test for Power Transformers

\section{Introduction}

The requirement of electric power is ever increasing for applications in hospitals, shopping malls, data centres, high rise residential buildings / offices etc. where reliable and safe operation of all the electrical equipments including transformer is essential. These equipments shall not explode to propagate a fire or emit toxic gases in case of a short circuit or similar incident. Oil filled transformers have several drawbacks for such applications and some problems are as below.

a. The oil filled transformer has a high amount of flammable liquid which can cause severe damage and loss of life when it bursts/explodes which generates toxic gases and heat.

b. Environmental issues of oil leak/spillage occur. Also disposal of oil at the end of the life is a problem.

c. Frequent maintenance issues.

Dry type transformers of various designs are appropriate to reduce the above issues and major types used are generally,

i. Open wound; which are generally preheated, varnished and baked.

ii. Vacuum Pressure Impregnation (VPI); where the windings are treated with a pressure and vacuum, then baked iii. Encapsulated dry type; where the open wound type transformer is encapsulated in an electrical grade insulating epoxy resin and silica powder.

iv. Cast resin transformer; in which the coils are casted in resin system under vacuum in a mould. The manufacturing process keeps the winding in epoxy resin and protects the transformer from severe environment.

The cast resin type dry type transformer is suitable for working in harsh environments where fire hazards also exist. The transformer shall be,

a. Suitable for storage, transportation and operation up to $-25^{\circ} \mathrm{C}$. (C2 class)

b. Suitable to work when exposed to condensate formation or contamination or both (E2 class)

c. Suitable for work in an environment where a fire hazard exists.

d. Transformer shall have reduced flammability to limit the fire hazard and the fire must be extinguished within specified conditions without toxic gas emission (F1 class)

In order to demonstrate that the transformer designed and manufactured meets the Climatic (C2), Environmental (E2) and fire withstand capability (F1) the C2E2F1 test is carried out at KEMA testing laboratory Netherlands which is described in this paper. 


\section{General Features of Cast Resin Transformer}

The cast resin dry type transformer is manufactured using Aluminium or Copper as winding material. The thermal class of insulation used predominantly is class $\mathrm{F}\left(155^{\circ} \mathrm{C}\right)$. Class $\mathrm{H}$ $\left(180^{\circ} \mathrm{C}\right)$ is also manufactured in specific applications. The resin system used consists of a predetermined combination of the following depending on the electrical, thermal \& fire withstand requirement (Table 1) [2]

Table 1. General Class-F Filled system.

\begin{tabular}{lll}
\hline Resin Component & Part by weight of mixture & Remarks \\
\hline Epoxy Resin & 100 \\
Hardener & 100 \\
Plasticiser & 10 \\
Filler & 350 \\
Accelerator & 0.3 & Colour shade as per requirement can be selected \\
Colour paste & 2.5 & \\
\hline
\end{tabular}

The resin used is an unmodified epoxy made by the reaction of Bisphenol $\mathrm{A}$ and Epichlorohydrin. Hardener is combination of anhydrides such as hexahydrophalic, tetrahydroptalic anhydride, phthalic anhydride etc. plasticizer (flexibiliser) is polypropelene glycol. Accelerator is aminophenol. [3]

\section{Specifications of the Tested Transformer}

1. Type-Dry type cast resin

2. $\mathrm{kVA}-1,600$

3. Phases-3

4. Rated frequency-50 $\mathrm{Hz}$

5. High voltage $-11,000 \mathrm{~V} \pm 2 \times 2.5 \%$ Delta

6. Low voltage-433 V Star

7. Connection-Dyn 11

8. Insulation level-LI $75 \mathrm{kVAC} 28 \mathrm{kV} / 3 \mathrm{kV}$

9. Insulation class-F

10. Type of cooling-AN

11. Impedance $\%-6$

12. Degree of protection of enclosure-IP 31

\section{Design Features of the Transformer}

\subsection{Core}

The core is manufactured from cold rolled grain oriented silicon steel laminations using "step lap" joints to reduce losses \& noise level. The core edges are given a protective coating of an epoxy, after assembly. The design of core is normal design and the maximum flux in the range of $1.7 \mathrm{~T}$

\subsection{Windings}

The LV and HV windings are manufactured from electrolytic quality copper foils with round edges. Interlayer insulation films of Class $\mathrm{F}$, capable to withstand $155^{\circ} \mathrm{C}$ are used during winding. The LV winding is Copper foil and have cooling ducts of $16 \mathrm{~mm}$ for giving a laminar airflow.

\subsection{Epoxy System}

Liquid, pre filled, low viscous, light base, hot curing, epoxy casting system is used to produce the transformer to meet Class C2 E2 F1 as per IEC 60076-11 [1]. The typical mechanical, electrical and physical parameters of this epoxy system when processed and cured with $66 \%$ filler are given in Table 2.

Table 2. Typical mechanical, electrical and physical parameters of epoxy system.

\begin{tabular}{lll}
\hline Parameter & Typical value & Unit \\
\hline Tensile strength & $40-50$ & $\mathrm{MPa}$ \\
Elongation at break & $0.65-0.85$ & $\%$ \\
Coefficient of thermal expansion (linear) & $50-60$ & $\mathrm{x} 10^{-6} / \mathrm{K}$ \\
Fume toxicity index & 1.67 & - \\
Smoke density & 0.05 & - \\
Water absorption of specimen at $23^{\circ} \mathrm{C}$ for & 0.28 & $\%$ by weight \\
10 days & $1.75-1.8$ & $\mathrm{~g} / \mathrm{cm} 3$ \\
Density & & \\
\hline
\end{tabular}

\section{Special Design Features}

\subsection{Features to Withstand C2 Test (Thermal Shock)}

The thermal expansion of conductor and resin will have to be perfectly same and also the conductor should not impart localized stresses on the resin. The precautions in design includes rounding off of conductor edges (for rectangular conductors \& foil), \& designing of the filler loading to get a coefficient of thermal expansion of the resin greater than two times the coefficient of thermal expansion of conductor material. Copper or aluminium is the conductor material being used for cast resin transformers. The same coefficient of thermal expansion for the resin and the conducting material is achieved by the adjusting filler loading in the resin.

The end clamping of the coils to the yoke shall have sufficient elasticity to withstand the effect of the linear expansion of the cast coil. The linear expansion due to the thermal shock of the cast coil can be approximately calculated by the following equation.

$$
\Delta L=\left(T_{2}-T_{1}\right) \propto_{1} L
$$

Where

$$
\Delta L=\text { Increase in length of coil m }
$$




$$
\begin{aligned}
& T_{2}=140{ }^{\circ} \mathrm{C}(\text { Finaltemperature }) \\
& T_{2}=25^{\circ} \mathrm{C}(\text { Initial temperature })
\end{aligned}
$$

$\alpha_{1}=16 \times 10^{-6} \mathrm{~m} /(\mathrm{mK}) \quad$ (Temperature coefficient of thermal expansion of resin system)

\section{$L=$ Axialheightofthecoil(castcoil)m}

The elasticity required for the end clamping system (both ends) shall be about ten percent more than $\Delta \mathrm{L}$. If excess elasticity is provided at the end clamping arrangement, the transformer may fail under short circuit.

\subsection{Features Needed to Withstand E2 (Environmental Test)}

The surfaces of the castings shall be smooth and distances between live terminals on the casting shall be designed to avoid tracking under humidity of more than $93 \%$ and exposure to conductive atmosphere.

The support blocks, dog bones, cylinders, resilient end clamps etc. will have to be selected suitablyto prevent tracking.

\subsection{Features to Withstand Fire Behaviour Test Class F1}

The total calorific value of the resin and other flammable materials in the coil \& insulation is one of the major criteria.

The filler loading determines the quantity of total resin in the casting. However, if the filler quantity is increased beyond a defined level, the transformer can fail in thermal shock test.

The resin, filler, support blocks, cylinder, dog bone etc. shall not contain corrosive and harmful gases such as hydrogen chloride, hydrogen cyanide, hydrogen bromide, hydrogen fluoride, sulphur dioxide, formaldehyde, etc.

\section{Test Procedures}

\subsection{Climatic Test for C2 Class (Thermal Shock Test)}

This test is to prove that the transformer is suitable for operation, transport and storage at an ambient temperature down to $-25^{\circ} \mathrm{C}$.

The complete transformer excluding enclosure is placed in a test chamber. The ambient temperature of the test chamber is measured at a minimum of 3 positions located $100 \mathrm{~mm}$ from the external surface and at half the height of the transformer. The average of the 3 readings is considered as the ambient temperature.

The test procedure is as below

a. The air temperature in the test chamber is gradually decreased to $(-25 \pm 3)^{\circ} \mathrm{C}$ in 8 hours and then maintained at this value for at least 12 hours.

b. A thermal shock performed by applying a current equal to two times the rated current to the windings contained in solid insulation. The current is maintained until the winding under test reaches a mean temperature corresponding to the average winding temperature plus maximum ambient temperature in normal service conditions. For the Class $\mathrm{F}$ transformer under test this is $100+40=140^{\circ} \mathrm{C}$. The mean temperature of the winding is measured by resistance variation.

c. The thermal shock can be applied by DC supply or AC supply. For the 1,600 kVA transformer as above, the test was carried out by applying direct current to the windings.

d. After the thermal shock, the transformer is brought back to a temperature of $(25 \pm 10)^{\circ} \mathrm{C}$.

e. At least 12 hours after the end of thermal shock test, the transformer is subjected to separate source voltage withstand test and induced over voltage test at $80 \%$ of the standard test values, and the transformer shall pass the tests. When visually inspected, the windings shall show no visible abnormality like cracks, slits, etc.

\subsection{Environmental Test Class E2}

This test includes a condensation test and a humidity penetration test.

\subsubsection{Condensation Test}

The transformer is placed in a test chamber of volume which is at least five times that of a rectangular box circumscribing the transformer. The humidity of the chamber is maintained above $93 \%$ and the conductivity of the water is kept in the range of $0.5 \mathrm{~S} / \mathrm{m}$ to $1.5 \mathrm{~S} / \mathrm{m}$.

The transformer shall be kept in the chamber for not less than 6 hours without energizing.

Within 5 minutes after the above, the transformer is subjected to an induced voltage test at 1.1 times the rated voltage for a period of 15 minutes, if the transformer winding is intended for connection to a solidly earthed system or a system earthed through low impedance. It is preferred to do the test in the test chamber.

\subsubsection{Humidity Penetration Test}

The transformer shall be in dry condition at the beginning of the test. The transformer is kept in the climatic chamber for 144 hours in de energised condition. The temperature of the chamber is held at $(50 \pm 3)^{\circ} \mathrm{C}$ and the relative humidity held at $(90 \pm 5) \%$.

At the end of 144-hour period and after 3 hours ( $\max$ ) in the ambient conditions, the transformer is subjected toinduce over voltage test and separate source withstand test at $80 \%$ of the standard values.

The transformer passes the test if there is no flashover or breakdown during the above dielectric tests and visual inspection does not show any serious tracking.

\subsection{Fire Behaviour Test for F1 Class}

\subsubsection{Preparation of Test Object}

The test is carried out on one complete phase of the transformer including HV \& LV coils, core limb, end insulation etc. The yoke \&enclosure, which is made of MS Steel having different IP classes of protection detailed in IEC 60076-11 [1] of the transformer etc. is not included. The outer coil dimensions are kept between $400 \mathrm{~mm}$ and $500 \mathrm{~mm}$. 


\subsubsection{Test Chamber}

Test Chamber as per IEC 60332-3-10 (2008) [2] with specified dimensions is used for the test. The main source of heat is ethyl alcohol of approximate calorific value of 27 $\mathrm{MJ} / \mathrm{kg}$ burning in a container. The quantity of alcohol would burn for about 20 minutes. The second source of heat is a vertically placed radiant electrical heater of $800 \mathrm{~mm} \times 500$ $\mathrm{mm}$ (width) made of $24 \mathrm{~kW}$ heater coil with adjustable power source to maintain the panel at $750^{\circ} \mathrm{C}$.

The airflow in the chamber is adjusted to about 0.21 $\mathrm{m} 3 / \mathrm{sec} \pm 15 \%$ at $20^{\circ} \mathrm{C}$.

\subsubsection{Test Method}

The container is filled with alcohol just before starting the test (typically 5 minutes). The radiant panel is switched on and the alcohol is ignited. The radiant panel is witched off after 40 minutes.

The following quantities are measured by means of thermocouples or equivalent at least for 60 minutes from the beginning of the test.

- Air inlet

- Air outlet

- Surface of LV coil at top

Surface of HV coil at top

- Core limb at bottom and top

- Duct between core \& LV coil in the middle

- Duct between LV \& HV coil in the middle

- Except the air inlet \& outlet temperature other readings are optional.

\subsubsection{Evaluation Criteria}

The transformer is considered to have passed the test if it meets the following criteria.

a. The temperature rise above ambient of the gases in the measuring section of the chimney shall not exceed 420 $\mathrm{K}$ throughout the test.

b. 5 minutes after the radiant panel is witched off (i.e. 45 minutes from the beginning of the test) the temperature rise above the ambient temperature of the gases in the measuring section shall not exceed $140 \mathrm{~K}$ and it shall decrease when measured over time periods of 10 minute.

c. The temperature rise of gases in the measuring section in the chimney shall not exceed $80 \mathrm{~K}$ after 60 minutes from the beginning of the test. These conditions are assumed to demonstrate that the fire has ceased to burn.

d. The arithmetic mean of the optical transmission factor of light in the measuring section, referred to an optical path through smoke of $1 \mathrm{~m}$, between 20 minute and 60 minute after the beginning of the test shall be not less than $20 \%$ of the optical transmission of light.

\section{Test Results of $1,600 \mathrm{kVA}$ Transformer}

C2, E2, F1 tests were carried out on a $1600 \mathrm{kVA} 11 / 0.433$ $\mathrm{kV}$ transformer at KEMA, testing laboratory (DNV-GL), Netherlands and the results are as follows.
The routine tests as per IEC 60076-11 [1] were carried out on the transformer prior to $\mathrm{C} 2 \mathrm{E} 2 \mathrm{~F} 1$ tests.

\subsection{Thermal Shock Test for C2 Class}

Temperature of test object at the end of cooling period is $25^{\circ} \mathrm{C}$. Test current through high voltage winding with 3 coils connected in series $2 x \operatorname{In}=96.97 \mathrm{~A}$ (DC). Test current through low voltage winding with 3 coils connected in series $2 x I n=4267$ A (DC). The temperature of the winding is determined by the resistance method and the test is continued till the calculated temperature reaches $140^{\circ} \mathrm{C}$.

Separate source AC voltage withstand test at $80 \%$ of the test voltage is applied to the transformer $(22.4 \mathrm{kV}$ on $\mathrm{HV}$ and $2.4 \mathrm{kV}$ on $\mathrm{LV}$ ) for 1 minute and there was neither flashover nor breakdown during these tests.

Induced over voltage test at $100 \mathrm{~Hz}$ for 1 minute was at $80 \%$ of the specified test level (693 volts phase to phase on low voltage winding) and there was neither flashover nor breakdown. Partial discharge measurement 3 minutes according to IEC 60076-11 [1] was carried out and partial discharges were not detected at $1.3 \mathrm{Ur}$.

\subsection{Environmental Test for E2 Class}

\subsubsection{Condensation Test}

The transformer was kept in a test chamber of $5 \times 5 \times 3 \mathrm{~m}$ size and the relative humidity of the room was kept above $93 \%$.

Atomised water Fine spray of water is atomising of water of conductivity $1.1 \mathrm{~s} / \mathrm{m}$ was applied to the test room and after 6 hours of condensation, the transformer was subjected to an induced over voltage test for 15 minutes at 1.1 times rated voltage (Applied voltage on LV was $476.3 \mathrm{~V}$ at $50 \mathrm{~Hz}$ ). There was no flashover during this application and visual inspection has not shown any tracking.

\subsubsection{Humidity Penetration Test}

The Transformer was kept in a test room $3.4 \times 5 \times 4 \mathrm{~m}$ size at $50^{\circ} \mathrm{C}$ and $90 \%$ relative humidity for 144 Hours. Separate source AC withstand voltage test at $80 \%$ test voltage was applied to the transformer $(22.4 \mathrm{kV}$ on $\mathrm{HV}$ Terminals for 1 minute and $2.4 \mathrm{kV}$ on LV Terminals for 1 minute at $50 \mathrm{~Hz}$ ).

The test voltage was applied within 3 hours after the humidity penetration test was stopped. There was neither flashover nor breakdown during the dielectric tests. Induced AC withstand voltage at $80 \%$ of test level was applied to the transformer (693 volts at $100 \mathrm{~Hz}$ for 1 minute). There was neither flashover nor breakdown during the test.

\subsection{Fire Behaviour Test F1}

\subsubsection{Checking of Corrosive and Harmful Gas Emission}

Small pieces of the cast coil are taken and placed in a combustion oven and heated to $800^{\circ} \mathrm{C}$ with heating rate of 40Degree per min. The gas flow during the test was 15 $\mathrm{mL} /$ minute. The gas is fed through an absorption liquid and then analysed. The traces of gases present in the cast resin sample are shown in table 3 
Table 3. Gases present in the cast resin sample.

\begin{tabular}{lll}
\hline Gas symbol & Name of gas & Concentration mg/g of resin \\
\hline $\mathrm{HCN}$ & Hydrogen Cyanide & $<0.01$ \\
$\mathrm{SO}_{2}$ & Sulphur Dioxide & $<0.01$ \\
$\mathrm{HCI}$ & Hydrogen Chloride & 0.058 \\
$\mathrm{HBr}$ & Hydrogen Bromide & $<0.01$ \\
$\mathrm{HF}$ & Hydrogen Fluoride & 0.08 \\
$\mathrm{HCHO}$ & Formaldehyde & $<0.01$ \\
\hline
\end{tabular}

\subsubsection{Fire Behaviour Test for F1 Class}

One complete phase of HV \& LV windings, core leg and insulation components was placed in the test chamber. The test results are as follows:
Table 4. Observations.

\begin{tabular}{ll}
\hline Time (minutes) & Observation \\
\hline 0 & Ignition of fire tray and switch on radiant panel \\
2 & First smoke above transformers \\
3 & Flame above transformers \\
8 & Smoke production decreases \\
15 & Fire tray extinguish \\
24 & Small flames between HV \& LV duct \\
27 & Flames out and smoke production minimal \\
40 & Switch off radiant panel \\
60 & Chamber door closed \\
\hline
\end{tabular}

Table 5. Test results.

\begin{tabular}{|c|c|c|c|}
\hline No & Requirement & Measured value & Remarks \\
\hline 1 & $\Delta \mathrm{T}$ Chimney $\leq 420^{\circ} \mathrm{C}$ throughout the test period & $389^{\circ} \mathrm{C}$ & Passed \\
\hline \multirow{2}{*}{2} & $\Delta \mathrm{T}$ Chimney $\leq 140^{\circ} \mathrm{C}$ at $45 \mathrm{~min}$. & $37^{\circ} \mathrm{C}$ & Passed \\
\hline & Temperature decrease over $10 \mathrm{~min}$. period & $8.6^{\circ} \mathrm{C} / 10$ minute & Passed \\
\hline 3 & $\Delta \mathrm{T}$ Chimney $\leq 80 \mathrm{~kg}$ at $60 \mathrm{~min}$ & $23.6^{\circ} \mathrm{C}$ All specified in degree Celsius only & Passed \\
\hline \multirow{2}{*}{4} & Arithmetic mean of optical transmission factor $>20 \%$ & $81 \%$ & Passed \\
\hline & Total mass of burnt material & $4 \mathrm{~kg}$ & - \\
\hline
\end{tabular}

\section{Conclusions}

The design of the $1600 \mathrm{kVA}$ cast resin transformer to withstand the $\mathrm{C} 2$, E2, F1 class of climatic, environmental and fire behaviour is verified by the tests conducted at independent laboratory. The results are complying with the requirement of the standard and validated the design.

\section{References}

[1] IEC 60076-11 - (2004) - dry type transformers.

[2] IEC 60332-3-10 - Test for vertical flame spread of vertically mounted bunched wires or cables.

[3] Hunstman datasheet for Araldite casting system.

[4] C57.12.91-2011 - IEEE Standard Test Code for Dry-Type Distribution and Power Transformers.

[5] C57.12.01-2015 - IEEE Standard for General Requirements for Dry-Type Distribution and Power Transformers.

[6] IEC 60076-1; 2011 Power Transformers part 1 General.

[7] IEC 60076-3 - Power Transformers Part 3 Insulation levels, dielectric test and external clearances.
[8] Federal Transformers - technical brochure "Cast Resin Transformers"

[9] IEC 60085 - Electrical insulation - Thermal evaluation and designation.

[10] IEC 60270 - High Temperature techniques - Partial Discharge Measurements.

\section{Biography}

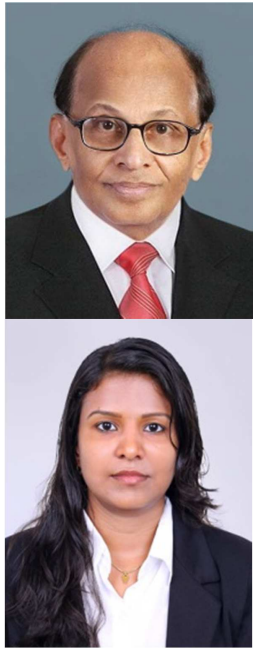

Muraleedharan Nair is the Chief Operating Officer of Federal Transformer group companies in Abu Dhabi, UAE. He has 49 years experience in transformer industry. $\mathrm{He}$ is an active member of IEEE and has presented technical papers in National and International seminars.

Remya Krishnan is a post graduate in Electronics Engineering from Calicut University, India. She is now working as Design Engineer with Federal Transformers Co., Abu Dhabi, UAE. She is an active participant in technical forums. 